\title{
Down-regulation of genes related to photoaging and inflammation in UVB- irradiated mice premature skin photoaging by linoleic acid-rich tempeh oil
}

\author{
Subali, D., Lay, B.W. and *Yanti \\ Faculty of Biotechnology, Atma Jaya Catholic University, Jalan Jenderal Sudirman 51, Jakarta 12930, \\ Indonesia
}

\author{
Article history: \\ Received: 29 March 2019 \\ Received in revised form: 31 \\ May 2019 \\ Accepted: 4 June 2019 \\ Available Online: 19 June \\ 2019
}

\section{Keywords:}

Matrix metalloproteinase-9 gene,

Photoprotective effect,

Polyunsaturated fatty acid,

Premature skin photoaging,

Tempeh oil

DOI:

https://doi.org/10.26656/fr.2017.3(6).137

\begin{abstract}
Polyunsaturated fatty acids (PUFAs) are natural substances that are considered for skin protection caused by UVB exposure. The increased levels of photoaging and inflammation markers, i.e. matrix metalloproteinases (MMPs), cyclooxygenase (COX)-2, and inducible nitric oxide synthase (iNOS) are correlated with the signs of photoaging and inflammation in the skin. Tempeh, one of the Indonesian fermented foods is a promising source of PUFAs for food applications including nutraceuticals and cosmeceuticals. In this study, PUFA-rich oil was extracted from white and black soybean tempeh and tested on its efficacy on down-regulating several genes related to photoaging and inflammation in UVB-irradiated premature skin aging in mice model by conducting hematoxylin and eosin (H\&E) staining and quantitative Real Time-PCR (qRT-PCR) assays. Tempeh oil was extracted in methanol and chloroform using Bligh and Dyer method, and PUFA constituents in tempeh oil were determined by pyrolysis gas chromatography-mass spectrometry (py/GC-MS) analysis. Mice skin dorsal was irradiated with UVB gradually for 4 weeks to induce premature photoaging. Mice were grouped into negative control; positive control; black soybean tempeh oil at 100 and $300 \mathrm{mg} / \mathrm{kg}$; white soybean tempeh oil at 100 and $300 \mathrm{mg} / \mathrm{kg}$; and omega 3 standard. Mice were orally supplemented with tempeh oil for 4 weeks along with UVB irradiation. The py/GC-MS profiling revealed that both tempeh oils contained major linoleic acid PUFA with 52.3\% in white tempeh oil and $85.69 \%$ in black tempeh oil, respectively. H\&E staining demonstrated that UVB irradiation caused premature skin photoaging in mice, indicating by necrosis, epidermal atrophy, and tissue damage. Orally tempeh oil treatment improved tissue damage and increased the proliferation of hair follicle in the skin. Tempeh oil was found to be effectively inhibited the genes expression of $M M P-1, M M P-3, M M P-9, C O X-2$ and $i N O S$ in UVB-irradiated mice skin. Among these genes, tempeh oil from black and white soybean tempeh exerted a significant effect on down-regulating the expression of $M M P-9$ gene in UVB-irradiated mice skin. In conclusion, tempeh oil may offer the promising photoprotective ingredient in application of nutraceuticals and cosmeceuticals for protecting skin photoaging.
\end{abstract}

\section{Introduction}

Photoaged skin or premature aging becomes one of most frequent dermatologic concern due to its symptoms, including irregular dryness, dark/light pigmentation, sallowness, deep furrows or severe atrophy, telangiectasia, premalignant lesions, laxity, and a leathery appearance. Other signs include elastosis and actinic purpura (Gilchrest, 1990). This skin can be associated with histological changes or disorganization of collagen caused by the activation of activator protein1 (AP-1), a transcription factor promoting collagen breakdown by up-regulating enzymes called matrix metalloproteinases (MMPs). These include MMP-1 (collagenase 1), which initiates degradation of fibrillar collagens types I and III, MMP-9 (gelatinase B), degrading collagen fragments generated by collagenases, and MMP-3 (stromelysin 1), degrading type IV collagen of the basement membrane and activating proMMP-1. Expression of MMP-1, MMP-3, and MMP-9 genes is induced following UV irradiation of human skin in vivo (Fisher et al., 1997). These observations are consistent with the induction of transcription factor AP-1 by UV irradiation and is accompanied with increased enzyme activities for each of the three MMPs (Fisher and 
Voorhees, 1998). MMP induction is, in part, responsible for UV-induced damage of skin connective tissue. Together, MMP-1, MMP-3, and MMP-9 have the capacity to completely degrade mature fibrillar collagen in the skin. Thus, UV irradiation of human skin causes extracellular matrix (ECM) degradation via induction of transcription factor AP-1 and subsequent increased MMP production. The UV radiation is absorbed by skin molecules and generates reactive oxygen species (ROS) causes oxidative damage to cellular components and the activation of MMPs. Each UV exposure induces a wound response with the subsequent imperfect repair, leaving an invisible solar scar. Repetitive UV exposure eventually leads to the development of a visible solar scar, manifested as a visible wrinkle over a lifetime (Lavker, 1995). Cyclooxygenase-2 (COX-2) inducible and nitric oxide synthase (iNOS) are important enzymes that mediate inflammatory processes. Improper upregulation of COX-2 and/or iNOS has been associated with pathophysiology of certain types of human cancers as well as inflammatory disorders (Surh et al., 2011). The UV exposure is one of the factors that up-regulates these proinflammatory enzymes (Nichols and Katiyar, 2010).

Several natural compounds have been targeting for photoaging strategic protection. Polyunsaturated fatty acid (PUFA) is one of the antiphotoaging candidates that have been found from plants, such as corn, flaxseed, almond, soybean, and chia seed. Deep sea fish like salmon, tuna, and marlin are the best source of PUFA from animal. According to Kostik et al. (2013), a nonfermented soybean as one of the PUFA source derived from plant contains $57.5 \%$ of PUFA, including oleic acid (28.5\%), linoleic acid (49.5\%), and linolenic acid (8\%). Few reports showed the potency of antiphotoaging effect from PUFAs. For example, eicosapentaenoic acid (EPA) as omega 3 fatty acid exerted anti-skin-aging effect and acted as a photoprotective agent in UVB-treated human skin in vivo by inhibiting UV-induced MMP-1 expression in human dermal fibroblasts (Kim et al., 2006). Recently, fermented foods have been explored for antiphotoaging candidates. It is believed that the fermentation process by selected microorganisms may also produce PUFA as one of the products. Barclay (2002) showed that the fermentation medium using euryhaline microorganisms effectively produced PUFAs. Thus, fermented foods could be considered as the new candidate for PUFA sources.

Tempeh is one of functional fermented food from Indonesia made from soybean Tempeh is made using white soybean fermented with Rhizopus microspores starter culture. Other beans could be also used for tempeh production, like black soybean and mung bean.
Black soybean tempeh is considered to have higher antioxidant activity than white soybean tempeh due to the anthocyanin contents in the skin of black soybean (Ghosh and Konishi, 2007). Tempeh is rich in isoflavone components, such as daidzein, glycitein, and genistein, thus, it offers the potency of anti-photoaging properties for nutraceutical and cosmeceutical applications. In addition, linolenic acid as one of omega 3 fatty acid found in soybean could be the main reason why tempeh is needed to be explored for its photoprotective effect against photoaging. In this study, the chemical profiling of natural oil rich in PUFAs extracted from white and black soybean tempeh was determined and tested its efficacy to inhibit several genes related to photoaging and inflammation in UVB-irradiated mice skin model in vivo.

\section{Materials and methods}

\subsection{Extraction and identification of tempeh oil}

Black and white soybean tempeh produced using organic soybean and packaged with banana leaves (Figure 1) were collected from traditional tempeh makers in Yogyakarta, Indonesia. Samples were ground and freeze-dried for $21 \mathrm{hrs}$. The homogenous powder was used for oil extraction according to the method of Lee et al. (2010). About $5 \mathrm{~g}$ of the sample was inserted to 50 $\mathrm{mL}$ conical tube and then added with $10 \mathrm{~mL}$ methanol and $5 \mathrm{~mL}$ chloroform. The sample mixture was homogenized and added with $5 \mathrm{~mL}$ chloroform. After that, the sample mixture was added with $10 \mathrm{~mL}$ of distilled water and homogenized until the mixture separated. The sample mixture was centrifuged $450 \mathrm{~g}$ for 10 mins. Chloroform fraction at the third layer was taken with a pipette and moved to a Petri dish, followed by drying it in a fume hood cupboard for $1.5 \mathrm{hrs}$. After the solvent evaporated, tempeh oil was transferred to a 1.5 $\mathrm{mL}$ vial and centrifuged $16000 \mathrm{x} g$ for $30 \mathrm{~s}$ to remove the pellet. The oil supernatant was measured to calculate the extraction efficiency. Tempeh oil identification was done according to the method of Mauren et al. (2016) using pyrolysis gas chromatography-mass spectrometry (py/ GC-MS) instrument (Shimadzu GCMS-QP2010, Kyoto, Japan) with helium as the carrier gas.

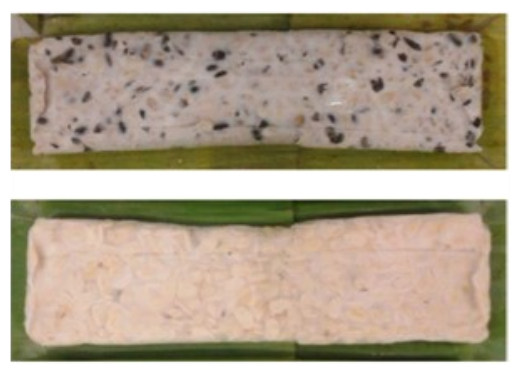

Figure 1. Black and white tempeh. 


\subsection{Intervention study and sample treatment}

Intervention study for photoaging model was conducted by using mice. The mice were housed in the group in sanitary ventilated animal rooms under controlled temperature $25 \pm 1^{\circ} \mathrm{C}, 60 \%$ relative humidity. All the mice were fed with water and standard feed $a d$ libitum. A total of 28 male mice (Mus musculus) strain DDY (Deutschland, Denken, and Yoken) aged 6 weeks were divided into groups including negative control (K-), positive control $(\mathrm{K}+)$, omega 3 standard (SO), black soybean tempeh oil at $100 \mathrm{mg} / \mathrm{kg}$ bw (HO100), black soybean tempeh oil at $300 \mathrm{mg} / \mathrm{kg}$ bw (HO300), white soybean tempeh oil at $100 \mathrm{mg} / \mathrm{kg}$ bw (PO100), and white soybean tempeh oil at $300 \mathrm{mg} / \mathrm{kg}$ bw (PO300) (Table 1). The mice were acclimatized for a week before the treatment and dorsal area of mice skin was shaved to give hairless condition. Photoaging mice modeling were done using UVB radiation every two days for 4 weeks gradually: $100 \mathrm{~mJ} / \mathrm{cm}^{2}$ for 10 mins in week-1, $150 \mathrm{~mJ} /$ $\mathrm{cm}^{2}$ for $15 \mathrm{mins}$ in week-2 and $200 \mathrm{~mJ} / \mathrm{cm}^{2}$ for $20 \mathrm{mins}$ in week-3 and 4 . The supplementation of tempeh oil was administered orally for 4 weeks along with UVB irradiation to investigate the exact photoprotective efficacy, and the dorsal part of mice skin was observed every week to visualize the morphology of aging and inflammation signs. Subsequently, mice were euthanized using ketamine-xylazine $(75 \mathrm{mg} / \mathrm{kg}$ bw $)$. The hairless dorsal skin and liver organ were collected for further analysis. The animal experiment was conducted at VStem Animal Facility (Bogor, Indonesia) and the protocol was approved by the Animal Welfare Supervision Commission and Use of Research Animals.

Table 1. Oral supplementation of tempeh oil from black and white soybean tempeh

\begin{tabular}{|c|c|c|}
\hline Group & UVB irradiation & Oral treatment \\
\hline $\mathrm{K}-$ & - & - \\
\hline $\mathrm{K}+$ & + & . \\
\hline HO 100 & + & $\begin{array}{l}100 \mathrm{mg} / \mathrm{kg} \text { bw black soybean } \\
\text { tempeh oil }\end{array}$ \\
\hline HO 300 & + & $\begin{array}{l}300 \mathrm{mg} / \mathrm{kg} \text { bw black soybean } \\
\text { tempeh oil }\end{array}$ \\
\hline PO 100 & + & $\begin{array}{l}100 \mathrm{mg} / \mathrm{kg} \text { bw white soybean } \\
\text { tempeh oil }\end{array}$ \\
\hline PO 300 & + & $\begin{array}{l}300 \mathrm{mg} / \mathrm{kg} \text { bw white soybean } \\
\text { tempeh oil }\end{array}$ \\
\hline $\mathrm{SO}$ & + & $300 \mathrm{mg} / \mathrm{kg}$ bw omega 3 standards \\
\hline
\end{tabular}

\subsection{Histopathology assay}

Histopathology assay for determining skin morphology was done using hematoxylin and eosin (H\&E) staining. Mice skin tissue sample was fixed with $10 \%$ formaldehyde for $24 \mathrm{hrs}$ and dehydrated with ethanol gradually at concentrations of $70,80,95$, and $100 \% \mathrm{v} / \mathrm{v}$. The tissue sample was observed and visualized in $100 \mathrm{X}$ magnification using a microscope.
2.4 Total RNA extraction and quantitative Real Time$P C R$ analysis ( $q R T-P C R)$

Analysis of qRT-PCR was used to measure the gene expression of photoaging and inflammation, including $M M P-1, M M P-3, M M P-9, C O X-2$, and $i N O S$ in UVBirradiated mice skin after treatment with orally tempeh oil supplementation. Total RNA from dorsal skin was extracted using GENEzol reagent (Geneaid, New Taipei, Taiwan) according to the protocol. At the beginning of this step, the sample was weighed to know the amount of reagent used (100 $\mu \mathrm{L}$ reagents for $10 \mathrm{mg}$ sample). Then, the sample was grinded with liquid nitrogen and homogenized with the buffer from kit. RNA concentration was measured using NanoDrop 1000 Spectrophotometer (Thermo Fisher Scientific, Wilmington, USA) then diluted into $1 \mu \mathrm{g} / \mathrm{mL}$. Then, cDNA synthesis was done using ReverTra Ace ${ }^{\circledR}$ qPCR RT Master Mix with gDNA remover according to the protocols.

The qRT-PCR for gene quantification was carried out using THUNDERBIRD ${ }^{\circledR}$ SYBR ${ }^{\circledR}$ qPCR Mix performed on iQ5 Multicolor Real Time PCR (BioRad) with beta-actin as internal control. Oligonucleotide primers were designed using the Primer-BLAST program from Natioal Center for Biotechnology Information (Table 2). About $20 \mu \mathrm{L}$ total volume reaction consisted of $10 \mathrm{~mL}$ THUNDERBIRD ${ }^{\circledR}$ SYBR ${ }^{\circledR}$ qPCR Mix (Toyobo, Osaka, Japan), $0.8 \mu \mathrm{L}$ primer for each forward and reverse $(0.3 \mu \mathrm{M}), 1 \mu \mathrm{L}$ cDNA template, and $7.4 \mathrm{~mL}$ nuclease free water. The thermal cycler condition was set 40 cycles with pre-denaturation at $95^{\circ} \mathrm{C}$ for $2 \mathrm{mins}$, denaturation at $95^{\circ} \mathrm{C}$ for $15 \mathrm{~s}$, annealing at $50{ }^{\circ} \mathrm{C}$ for $30 \mathrm{~s}$, and elongation at $72^{\circ} \mathrm{C}$ for $30 \mathrm{~s}$. All gene expression values were normalized to $\beta$ actin house keeping gene. Expression levels were calculated by relative quantification using the $2^{-\Delta \Delta C}{ }_{T}$ method, which the data were log-transformed (log base of 2) and alterations with respect to the UVB-irradiated premature skin photoaging control group were displayed as log-fold changes (Maness, 2015).

\subsection{Statistical analysis}

The experiments were done triplicate for this study. All data are presented as the means \pm standard deviation. Data were evaluated using the one way-analysis of variance test and Tukey test. The difference between the fold change (double delta $\mathrm{CT}$ ) means was considered significant when $\mathrm{P} \leq 0.05$.

\section{Results}

3.1 Chemical profiling of tempeh oil by py/GC-MS

Oil extracted from white and black soybean tempeh 
had 6.7 and $8.0 \% \mathrm{w} / \mathrm{v}$ of yield extraction. Chemical profiling of oil in white and black soybean tempeh by py/ GC-MS was shown in Figure 2. The chromatograms showed that the major compound in the tempeh oil was linoleic acid (LA), a PUFA that is also known as omega 6 fatty acid (Table 3 ). In white soybean tempeh oil, the LA content was $52.3 \%$, while in black soybean tempeh, it was $85.69 \%$, respectively. In addition, white soybean tempeh oil also had a monounsaturated fatty acid (MUFA) called methyl petroselinate with concentration of $40.09 \%$.

\subsection{Effect of tempeh oil on UVB-irradiated mice skin photoaging by $H \& E$ staining}

Tempeh oil had no significant visual effect on morphology of skin mice after irradiated with UVB (data not shown). Meanwhile, histopathology data using H\&E staining revealed that mice skin irradiated with UVB $(\mathrm{K}+)$ exerted several differences in histological characteristics before and after treatment with tempeh oil (Figure 3). Positive control group $(\mathrm{K}+)$ revealed necrosis in mice tissues, indicating the photoaging symptom. After orally supplementation with white and black tempeh oil (HO and PO), the necrosis in tissue was effectively inhibited, followed by the improved condition of epidermal tissues, hair follicles, and dermal tissues. In addition, oral treatment of black and white tempeh oil also promoted proliferation of hair follicles and protected skin from epidermal atrophy, indicated by the thinning and wrinkled epidermis. Interestingly, our data showed that tempeh oil had similar potency with the omega 3 standard (SO).

3.3 Effect of tempeh oil on the expression of genes related to photoaging and inflammation in UVBirradiated mice skin photoaging by qRT-PCR

Gene expression of photoaging and inflammation, including $M M P-1, M M P-3, M M P-9, C O X-2$, and $i N O S$ in UVB-irradiated mice skin was quantified by qRTPCR (Figure 4). Orally treatment of black soybean tempeh oil at $300 \mathrm{mg} / \mathrm{kg}$ bw (HO300) strongly downregulated the gene expression of $M M P-1$ and $M M P-9$ up to 3.5 times compared to that of control in mice skin treated with UVB (Figures 4a and 4c). Meanwhile, oral supplementation of white soybean tempeh oil at low dose (100 $\mathrm{mg} / \mathrm{kg}$ bw; PO100) was found to be more

Table 2. Oligonucleotide primer sequences

\begin{tabular}{lllc}
\hline \multicolumn{1}{c}{ Gene } & \multicolumn{1}{c}{ Forward } & \multicolumn{1}{c}{ Reverse } & Size (bp) \\
\hline$M M P-1$ & GTTGGAGCAGGCAGGAAGGAG TTGCCTCAGCTTTCAGCCAT & 245 \\
$M M P-3$ & GGCGCAAATCTCTCAGGACT & TTCTTCACGGTTGCAGGGAG & 217 \\
$M M P-9$ & AAAGGCAGCGTTAGCCAGAA & TTGGAATCGACCCACGTCTG & 362 \\
$C O X-2$ & CTTCGGGAGCACAACAGAGT & GGGGTGCCAGTGATAGAGTG & 252 \\
$i N O S$ & TGCCAGGGTCACAACTTTACA & TGAGAACAGCACAAGGGGTT & 335 \\
-actin & AGGGAAATCGTGCGTGACAT & ACTGTGTTGGCATAGAGGTC & 278 \\
\hline
\end{tabular}

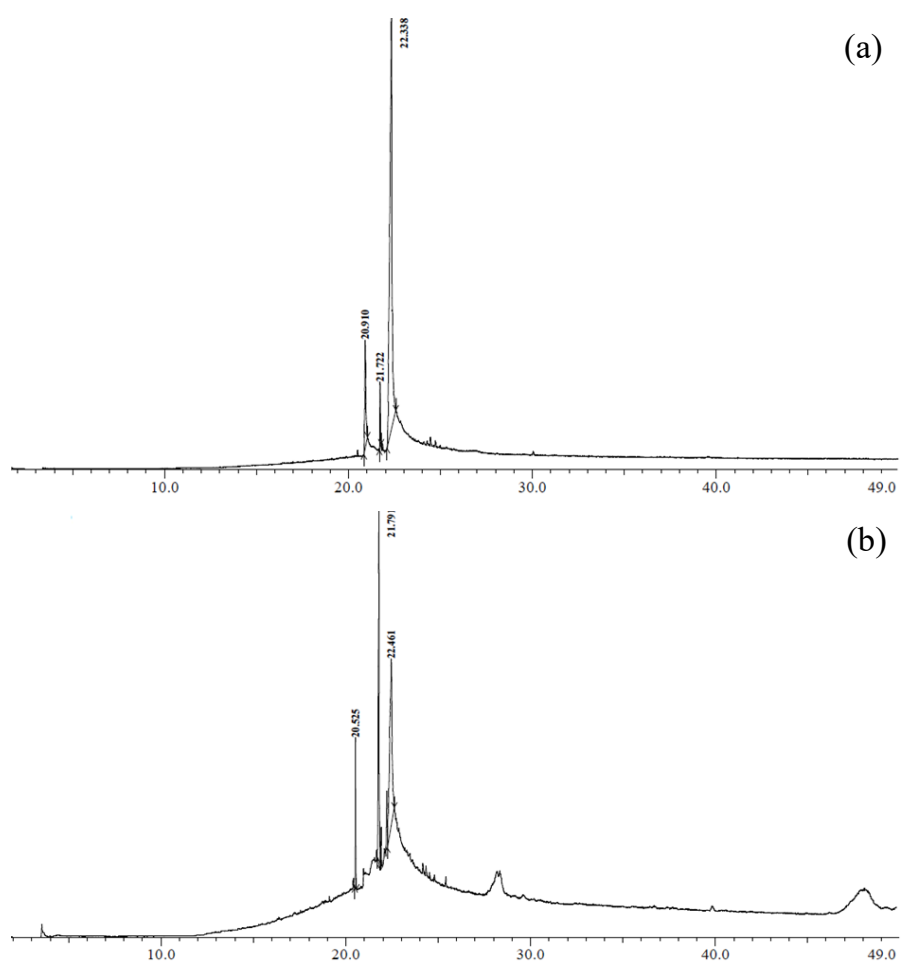

Figure 2. Identification of PUFA-rich tempeh oil from black (a) and white soybean tempeh (b) by py/GC-MS.

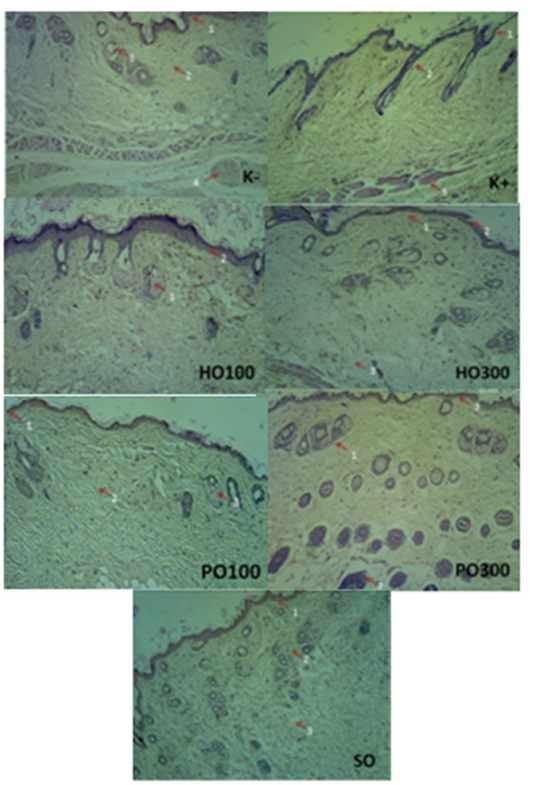

Figure 3. Histology profiles of skin tissues after treatment with tempeh oil for 4 weeks by $\mathrm{H} \& \mathrm{E}$ staining. The treatment groups included non-UVB treated mice $(\mathrm{K}-)$, UVB treated mice $(\mathrm{K}+)$, orally supplemented: $100 \mathrm{mg} / \mathrm{kg}$ bw black soybean tempeh oil (HO100), $300 \mathrm{mg} / \mathrm{kg}$ bw black soybean tempeh oil (HO300), $100 \mathrm{mg} / \mathrm{kg}$ bw white soybean tempeh oil (PO100), $300 \mathrm{mg} / \mathrm{kg}$ bw white soybean tempeh oil (PO300), and $300 \mathrm{mg} / \mathrm{kg}$ bw omega 3 standard (SO). $\mathrm{n}=4$ for each group.

C 2019 The Authors. Published by Rynnye Lyan Resources 
significant to inhibit the expression of $M M P-9$ genes up all genes related to photoaging and inflammation in to 4.5 times in comparison to that of control (Figure 4c). UVB-irradiated mice skin by orally black soybean and Most other genes (MMP-3, COX-2, and $i N O S)$ were white soybean tempeh oil (PO and $\mathrm{HO})$ showed similar inhibited by both tempeh oil approximately 1.5-2.5 times efficacy with omega 3 standard (SO). compared to that of control. Overall, down-regulation of

Table 3. Identification of PUFA-rich tempeh oil from black and white soybean tempeh by py/GC-MS

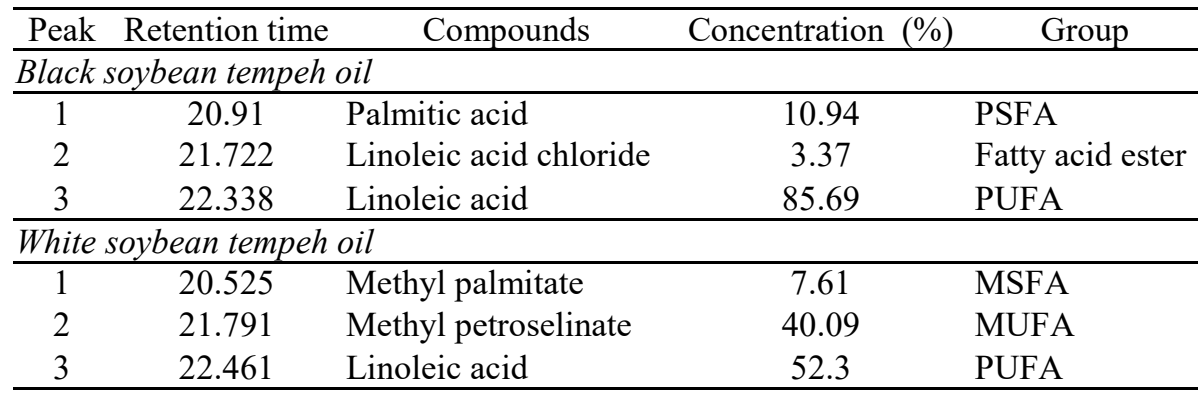

PSFA - polysaturated fatty acid; PUFA - polyunsaturated fatty acid; MSFA - monosaturated fatty acid; MUFA - monounsaturated fatty acid
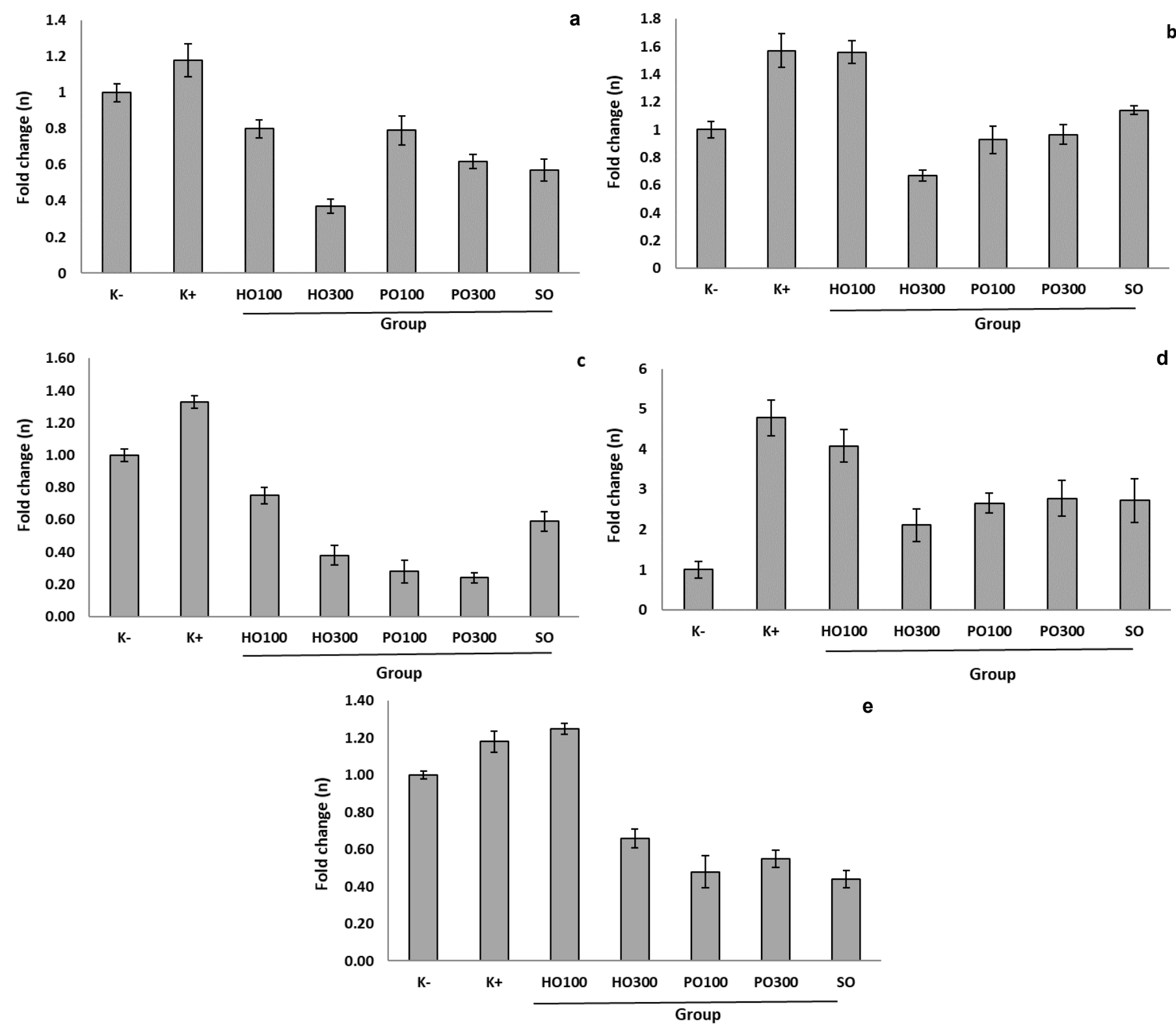

Figure 4. Effect of tempeh oil on the expression of genes related to photoaging and inflammation, including MMP-1 (a), MMP3 (b), MMP-9 (c), COX-2 (d), and iNOS (e) in UVB-irradiated mice skin. The treatment groups included non-UVB treated mice (K-), UVB treated mice (K+), orally supplemented: $100 \mathrm{mg} / \mathrm{kg}$ bw black soybean tempeh oil (HO100), $300 \mathrm{mg} / \mathrm{kg}$ bw black soybean tempeh oil (HO300), $100 \mathrm{mg} / \mathrm{kg}$ bw white soybean tempeh oil (PO100), $300 \mathrm{mg} / \mathrm{kg}$ bw white soybean tempeh oil (PO300), and $300 \mathrm{mg} / \mathrm{kg}$ bw omega 3 standard (SO). $\mathrm{N}=4$ for each group. 


\section{Discussion}

For extraction of oil from tempeh, we employed Bligh and Dyer method using chloroform and methanol at ratio of 1:1 (Lee et al., 2010) and obtain the yield of extraction approximately $6.7-8.0 \%$ for black and white tempeh oil extraction. Meanwhile, Cravotto et al. (2007) showed that heated homogenized tempeh only produces $3.5 \%$ yield of tempeh oil with the similar method. It is noted that tempeh powder obtained by freeze-drying method had higher yield of tempeh oil either for white soybean tempeh and black soybean tempeh in comparison with the homogenized tempeh one. Thus, we suggest that Bligh and Dyer method could be modified with freeze-drying method for obtaining the higher yield of tempeh oil extraction.

For chemical compound identification, our findings showed that the major component in tempeh oil extracted from black and white soybean tempeh was linoleic acid (Figure 2). Linoleic acid is a PUFA known as omega 6 fatty acid. White soybean tempeh oil had $52.3 \%$ content of linoleic acid, while the black one had higher linoleic acid up to $85.69 \%$ (Table 3). It is noted that extraction of tempeh oil rich in PUFA using Bligh and Dyer method modified with freeze-dry technique is an effective way to obtain high yield of PUFA type linoleic acid from black and white soybean tempeh with less impurities. Compared to the unfermented soybean, report by Kostik et al. (2013) showed that non-fermented white soybean oil contained linoleic acid (49.5\%), and linolenic acid (8\%). In line with our data (Figure 2 and Table 3), most reports showed the linoleic acid is known as the predominant fatty acid in non-fermented white soybean with average concentration of $53 \%$. However, there is no report about the fatty acid content in non-fermented black soybean.

Alpha linolenic acid (omega 3 fatty acid) was not found in both black and white soybean tempeh due to various changes occurred in fatty acid composition of bean during maturation (Privett et al., 1973). The percentages of stearic and palmitic acids were relatively high in the initial stages of the development of the bean and then decreased rapidly as the bean developed. The percentages of oleic and linoleic acids were initially low but continued to increase throughout the development of the bean. In contrast, linolenic acid increased rapidly in the initial stage and then decreased. Soybean fermentation in tempeh could be the other reason for the absence of alpha linolenic acid in tempeh. Several studies showed that Rhizopus sp. and other microorganisms' activity in tempeh may contribute to the change of soybean nutrition in particular complex nutrition into simple nutrition (Koh et al., 2012).
UVB radiation in dorsal part of mice skin $(\mathrm{K}+)$ for 4 weeks did not reveal the tissue damage as sign of aging and inflammation. In linear, oral supplementation of tempeh oil did not change the morphology of mice skin after irradiation by UVB (data not shown). According to Sumiyoshi et al. (2009), inflammation symptoms such as redness, thickness, elasticity degradation, and wrinkle in mice skin were showed morphologically after 8 weeks of UVB radiation. Thus, the exposure of UVB in mice dorsal skin for 4 weeks treatment only caused premature skin photoaging condition visually.

In contrast, histopathology results using $\mathrm{H} \& \mathrm{E}$ staining showed the significant impacts of orally tempeh oil supplementation on protection of photoaging and inflammation in UVB-irradiated mice skin (Figure 3). Proliferation of hair follicles in mice skin after treatment using orally tempeh oil was a positive sign of tissue repair. In term of dose, our data showed that mice group with high dose treatment of black and white soybean tempeh oil (HO300 and PO300) showed higher effects proliferation of hair follicle and tissue repair than that of the low dose one (HO100, PO100, and SO). Khavkin and Ellis (2011) reported that high dose of sample treatment caused epidermal atrophy in mice photoaging model. Similar to our results, orally treatments with high dose of tempeh oil and omega 3 standard (HO300, PO300, and SO) gave mice a partial epidermal atrophy as a sign of photo-aged skin. Interestingly, study by Baker Jr. and Ciotti (2012) showed that treatment of topical nanoemulsion cream containing $18 \%$ of non-fermented soybean oil also exerted anti-wrinkle and antiaging effects in vivo. This study employed the cross-section view of the pilosebaceous unit in hamster ear after application of nanoemulsion plus fluorescein compared to that of control. Thus, these data indicate that nonfermented soybean may also have the similar potency with fermented soybean tempeh as antiaging candidate.

Orally tempeh oil treatment was also further studied for its potency on down-regulating the expression of genes related to photoaging and inflammation in UVBirradiated mice skin (Figure 4). Both tempeh oil significantly showed the significant inhibition of $M M P$ genes particularly $M M P-9$ genes compared to that of control $(\mathrm{K}+)$ in mice skin treated with UVB. Downregulation of $M M P$ genes implied that tempeh oil had the potency to suppress activator protein (AP)-1 transcription factor activity that had function as MMP gene activator (Fisher et al., 1997). Blocking MMP expression may contribute to the inhibition of ECM degradation in mice skin. These results are in linear with histopathology data (Figure 3) that showed skin tissue repair after orally treatment with tempeh oil for 4 weeks. Further study is needed to know about the exact 
mechanism of tempeh oil inhibition in ECM degradation.

Comparing white and black tempeh oil treatment in protecting UVB-irradiated mice skin, our findings indicate that higher dosage of black tempeh oil $(300 \mathrm{mg} /$ $\mathrm{kg} \mathrm{bw}$ ) showed more significant down-regulating effect on gene expression compared to that of white tempeh oil and black tempeh oil at lower dosage $(100 \mathrm{mg} / \mathrm{kg})$ (Figure 4). It is noted that anthocyanin contents in black soybean protect the skin from UVB radiation, while white soybean did not have this compound. Tsoyi et al. (2008) reported that anthocyanin in black soybean protected hairless mice from cell apoptosis caused by UVB radiation. The role of PUFAs especially linoleic acid for photoaging protection is needed to be more investigated. Interestingly, other reports demonstrated that omega 6 fatty acids may help to improve skin health through inducing the migration of human mesenchymal stem cells by MT3-MMP-mediated fibronectin degradation (Oh et al., 2015). Thus, we assume that down-regulation of $M M P S$ gene expression in UVBirradiated mice skin may be correlated with the action of omega 6 fatty acids-rich tempeh oil in skin regeneration via the similar mechanism. Taguchi et al. (2014) also proved that high contents of linoleic acid in safflower oil (73.2\%) effectively suppressed the expression of $M M P-9$ gene in cancer-associated fibroblasts in vitro and in vivo.

Based on our data, we assume that photoprotective effect of tempeh on photoaging gene expression may be linked with the fermentation process of soybean. Fermentation may result in the increase of active compound production in fermented soybean, including fatty acids and isoflavones contents. Oral supplementation of tempeh oil extracted from fermented black soybean with $>85 \%$ of LA content significantly ameliorated the gene expression of $M M P-1$ and $M M P-9$ in UVB-irradiated mice skin, while tempeh from fermented white soybean with $\sim 52 \%$ of LA concentration exerted the significant down-regulating effect on $M M P-9$ gene expression (Figure 4). However, most previous reports were focused on anti-photoaging effect on downregulating photoaging markers at protein levels. For example, Huang et al. (2010) demonstrated that isoflavones in tempeh exerted anti-photoaging effect by attenuating COX-2 inhibition and proliferating cell nuclear antigen (PCNA) expression in UVB-irradiated mice skin. Other study by Lee et al. (2014) also reported that fermented soybean containing genistein and daidzein suppressed UVB-induced skin inflammation in hairless mouse by downregulating the expression of COX-2 and iNOS at protein levels. The latest report by Shin et al. (2017) demonstrated that combination of soybean extract and haematococcus extract effectively prevented UVBinduced photoaging through downregulation of MMP-1 gene and protein expression.

Moreover, our findings indicated that tempeh oil extracted from black and white soybean did not have omega 3 PUFA content (Figure 2 and Table 3). However, omega 6 PUFA as the major fatty acid found in tempeh oil has a particular role in structural integrity and barrier function of the skin. Both omega 3 and omega 6 PUFAs are essential to induce the potent signal molecules called eicosanoids that may influence the inflammatory response of the skin and reduce photoaging. Efficacy of linoleic acid on improving the longevity of red blood cell membranes in vivo was also reported by Phetcharat et al. (2015). Unfortunately, based on the py/GC-MS profiling (Figure 2 and Table 3), there were no antioxidants like tocopherol and phenolic compounds found in tempeh oil. It seems that these agents had unstable characteristics in high temperature. Tocopherol and phenolic compounds are antioxidants with main function for neutralizing reactive oxygen species (ROS) in order to prevent cell damage and inflammation (Rahman, 2007; Decker et al., 2010). For further identification of antioxidants in tempeh oil that are also responsible to prevent photoaging and inflammation caused by UVB irradiation, liquidchromatography-mass spectrometry (LC-MS) instrument could be employed for advanced detection of these compounds in tempeh because it can work at lower temperature than that of the py/GC-MS one (Hoppe et al., 1997).

In addition, omega 3 standard from commercial fish oil was also proven to act as a photoaging protector from UVB irradiation by downregulating the genes of MMPs, $C O X-2$ and $i N O S$ in UVB-irradiated mice skin (Figure 4). Omega 3 such EPA prevents systemic immune suppression as a result from UVB irradiation. According to Moison and Henegouwen (2001), EPA could modulate immune responsiveness, however, due to their susceptibility to ROS-induced cell damage, it can also challenge the epidermal antioxidant defense system. The high gene expression related to photoaging and inflammation in control group $(\mathrm{K}+)$ after irradiation with UVB for 4 weeks indicated that UVB significantly upregulated the expression of photoaging and inflammation genes, although it did not affect the morphology of skin mice (Figures 3 and 4).

\section{Conclusion}

Our results suggest that tempeh oil extracted from black and white soybean tempeh contained major linoleic acid PUFA, improved skin damage and increased proliferation of hair follicle in UVB-irradiated mice skin through down-regulating the genes expression 
related to photoaging and inflammation in particular $M M P s$ genes. Our finding showed that tempeh oil from fermented black soybean at $300 \mathrm{mg} / \mathrm{kg}$ bw significantly down-regulated the gene expression of $M M P-1$ and $M M P-9$ in UVB-irradiated mice skin. Tempeh oil may be potentially applied as a photoprotector ingredient in application of cosmeceuticals and nutraceutical for skin photoaging protection.

\section{Conflict of Interest}

The authors declared there is no conflict interest. The authors alone are responsible for the content of the paper.

\section{Acknowledgement}

The research was supported by Atma Jaya Research and Community Service Center through Competitive Research Grant (2016), Atma Jaya Catholic University of Indonesia.

\section{References}

Baker Jr., J.R. and Ciotti, S.M. (2012). U.S. Patent No. US20120064136A1. Washington, DC: U.S. Patent and Trademark Office.

Barclay, W.R. (2002). U.S. Patent No. 6,451,567. Fermentation process for producing long chain omega-3 fatty acids with euryhaline microorganisms. Washington, DC: U.S. Patent and Trademark Office.

Cravotto, G., Boffa, L., Mantegna, S., Perego, P., Avogadro, M. and Cintas, P. (2007). Improved extraction of vegetable oils under high-intensity ultrasound and/or microwaves. Ultrasonics Sonochemistry, 15(5), 898-902. https:// doi.org/10.1016/j.ultsonch.2007.10.009

Decker, E.A., Elias, R.J. and McClements, D.J. (2010). Oxidation in Foods and Beverages and Antioxidant Applications. Amsterdam: Elsevier Science. https:// doi.org/10.1533/9780857090447

Fisher, G.J., Wang, Z.Q., Datta, S., Varani, J., Kang, S. and Voorhees, J.J. (1997). Pathophysiology of premature skin aging induced by ultraviolet light. The New England Journal of Medicine, 337, 14191428. NEJM199711133372003

Fisher, G.J. and Voorhees, J.J. (1998). Molecular mechanisms of photoaging and its prevention by retinoic acid: ultraviolet irradiation induces MAP kinase signal transduction cascades that induce AP-1 -regulated matrixmetalloproteinases that degrade human skin in vivo. Journal of Investigative Dermatology, 3(1), 61-68. https://doi.org/10.1038/ jidsp. 1998.15
Ghosh, D. and Konishi, T. (2007). Anthocyanins and anthocyanin-rich extracts: role in diabetes and eye function. Asia Pacific Journal of Clinical Nutrition, 16(2), 200-208.

Gilchrest, B.A. (1990). Skin aging and photoaging. Dermatology Nursing, 2, 79-82.

Hoppe, M.B., Jha, H.C. and Egge, H. (1997). Structure of an antioxidant from fermented soybeans (tempeh). Journal of the American Oil Chemists' Society, 74 (4), 477-479. https://doi.org/10.1007/s11746-997$0110-4$

Huang, C.C., Hsu, B.Y., Wu, N.L., Tsui, W.H., Lin, T.J., Su, C.C. and Hung, C.F. (2010). Anti-photoaging effects of soy isoflavone extract (aglycone and acetylglucoside form) from soybean cake. International Journal of Molecular Science, 11(12), 4782-4795. https://doi.org/10.3390/ijms11124782

Khavkin, J. and Ellis, D.A. (2011). Aging skin: histology, physiology, and pathology. Facial Plastic Surgery Clinics of North America, 19(2), 229-234. http://dx.doi.org/10.1016/j.fsc.2011.04.003

Kim, H. H., Cho, S., Lee, S., Kim, K.H., Cho, K.H., Eun, H.C. and Chung, J.H. (2006). Photoprotective and anti-skin-aging effects of eicosapentaenoic acid in human skin in vivo. Journal of Lipid Research, 47 (5), 921-930. https://doi.org/10.1194/jlr.M500420JLR200

Koh, S.P., Jamaluddin, A, Mohamed Alitheen, N.B., Mohd Ali, N., Mohd Yusof, H. and Long, K. (2012). Nutritional values of tempe inoculated with different strains of Rhizopus: its $\gamma$-aminobutyric acid content and antioxidant property. Journal of Tropical Agriculture and Food Science, 40(2), 181-192.

Kostik, V., Memeti, S. and Bauer, B. (2013). Fatty acid composition of edible oils and fats. Journal of Hygienic Engineering and Design, 4, 112-116.

Lavker, R.M. (1995). Cutaneous aging: chronologic versus photoaging. In Gilchrest, B.A. (Ed), Photodamage, p. 123-135. New Jersey: Wiley-Blackwell.

Lee, J.Y., Yoo, C., Jun, S.Y., Ahn, C.Y. and Oh, H.M. (2010). Comparison of several methods for effective lipid extraction from microalgae. Bioresource Technology, 101(1), 575-577. https:// doi.org/10.1016/j.biortech.2009.03.058.

Lee, T.H., Do, M.H., Oh, Y.L., Cho, D.W. Kim, S.H. and Kim, S.Y. (2014). Dietary fermented soybean suppresses UVB-induced skin inflammation in hairless mice via regulation of the MAPK signaling pathway. Journal of Agricultural and Food Chemistry, 62(36), 8962-8972. http:// dx.doi.org/10.1021/jf5018252 
Maness, L.R. (2015). The effect of butyric acid on gene expression of GLUT2 and IRS1 on human hepatocytes in vitro. Advances in Diabetes and Metabolism, 3(1), 7-10.

Mauren, F.M., Yanti and Lay, B.W. (2016). Efficacy of oral curcuminoid fraction from Curcuma xanthorrhiza and curcuminoid cider in high-cholesterol fed rats. Pharmacognosy Research, $8(3), \quad 67-73 . \quad$ https://doi.org/10.4103/09748490.181468

Moison, R.M. and Beijersbergen van Henegouwen, G.M. (2001). Dietary eicosapentaenoic acid prevents systemic immunosuppression in mice induced by UVB radiation. Radiation Research, 156(1), 36-44.

Nichols, J.A. and Katiyar, S.K. (2010). Skin photoprotection by natural polyphenols: antiinflammatory, antioxidant and DNA repair mechanisms. Archives of Dermatological Research, 302(2), 71-83. https://doi.org/10.1007/ s00403-009-1001-3

Oh, S.Y., Lee, S.J., Jung, Y.H., Lee, H.J. and Han, H.J. (2015). Arachidonic acid promotes skin wound healing through induction of human MSC migration by MT3-MMP-mediated fibronectin degradation. Cell Death and Disease, 6(5), 1750. https:// doi.org/10.1038/cddis.2015.114

Phetcharat, L., Wongsuphasawat, K. and Winther, K. (2015). The effectiveness of a standardized rose hip powder, containing seeds and shells of Rosacanina, on cell longevity, skin wrinkles, moisture, and elasticity. Clinical Interventions in Aging, 10, 18491856. https://doi.org/10.2147/CIA.S90092

Privett, O.S., Dougherty, K.A., Erdahl, W.L. and Stolyhwo, A. (1973). Studies on the lipid composition of developing soybeans. Journal of the American Oil Chemists' Society, 50(12), 516-520. https://doi.org/10.1007/BF02640523

Rahman, M.S. (2007). Handbook of Food Preservation. $2^{\text {nd }}$ ed. Florida: CRC Press. https:// doi.org/10.1201/9781420017373

Shin, J., Kim, J.E., Park, K.J., Kang, J.I., Kim, T.S., Lee, S.Y., Yeo, I.H., Park, J.H., Kim, J.H., Kang, N.J. and Lee, K.W. (2017). A combination of soybean and Haematococcus extra ct alleviates ultraviolet B-induced photoaging. International Journal of Molecular Science, 18(3), 1 -13. http://doi.org/ 10.3390/ijms18030682.

Sumiyoshi, M., Hayashi, T. and Kimura, Y. (2009). Effects of the non-sugar fraction of brown sugar on chronic ultraviolet B irradiation-induced photoaging in melanin-possessing hairless mice. Journal of Natural Medicines, 63(2), 130-136. https:// doi.org/10.1007/s11418-008-0301-9

Taguchi, A., Kawana, K., Tomio, K., Yamashita, A., Isobe, Y., Nagasaka, K., Koga, K., Inoue, T., Nishida, H., Kojima, S. and Adachi, K. (2014). Matrix metalloproteinase (MMP)-9 in cancerassociated fibroblasts (CAFs) is suppressed by omega-3 polyunsaturated fatty acids in vitro and in vivo. PLoS One, 9(2), 1-7. https://doi.org/10.1371/ journal.pone.0089605

Tsoyi, K., Park, H.B., Kim, Y.M., Chung, J.I., Shin, S.C., Shim, H.J., Lee, W.S., Seo, H.G., Lee, J.H., Chang, K.C. and Kim, H.J. (2008). Protective effect of anthocyanins from black soybean seed coats on UVB-induced apoptotic cell death in vitro and in vivo. Journal of Agricultural and Food Chemistry, 56(22), 10600-10605. https://doi.org/10.1021/ jf802112c 